\title{
Bienvenida la lectura
}

\author{
Welcome to reading
}

\author{
Parrodi-Mayorga ML, * Encalada-Díaz MI
}

«No todos los lectores son líderes, pero todos los líderes son lectores»

Harry S. Truman

Estimados colegas, es una enorme satisfacción poner al alcance de los médicos ortopedistas esta revista, que tiene como propósito principal convertirse en una herramienta que sirva para dar cauce a las inquietudes que van surgiendo en el oficio que practicamos y que al mismo tiempo ofrezca posibilidades reales de compartir las experiencias afortunadas entre los que ejercemos esta profesión.

Si bien como profesionistas tuvimos una formación universitaria, que exigió esfuerzo y constancia, condiciones que permanecieron durante la especialidad y que una vez concluida siguen vigentes en la práctica profesional, hoy se hacen indispensables y señalan la calidad profesional de quienes las llevan a cabo.

El perfil de egreso de la especialidad, en muchas instituciones hospitalarias, pone énfasis en la docencia e investigación y en las competencias que debe mostrar el especialista, entre ellas la aplicación teórica en que se fundamenta la investigación médica; también señala las habilidades y destrezas adquiridas, entre las que se encuentra el uso de diversas modalidades educativas para su actualización, es decir, se sabe responsable de la necesidad del autoaprendizaje.

Además, agrega el perfil, entre las actitudes que lo distinguen está la disposición de renovar sus conocimientos en forma continua y la participación en eventos que favorezcan su desarrollo personal y el de la especialidad, excelentes oportunidades para el intercambio de experiencias profesionales en beneficio de los pacientes.

Abraham Lincoln señala: «Todas las cosas que deseas saber están en los libros». Nunca como hoy la frase es cierta, las posibilidades de leer se han extendido y van mucho más allá de los libros tradicionales, hoy disponemos de libros electrónicos traducidos a muchas lenguas en los que podemos satisfacer la exigencia de estar actualizado en el campo de desempeño de la Ortopedia.

Reconocemos los beneficios que brinda la lectura en todas sus modalidades, no sólo como herramienta para obtener conocimientos y aplicarlos, lo que probaremos en cada una de las participaciones de los colaboradores; además, la publicación cuenta con un espacio reservado a la retroalimentación, en donde esperamos las aportaciones y sugerencias de los lectores, que seguramente enriquecerán el contenido de la revista.

\section{WwW medigraphic.org.mx}

\footnotetext{
* Maestría en Innovaciones Educativas de la Universidad La Salle. Diplomado en Literatura Latinoamericana de la UNAM. México.

* Editor en Jefe, Acta Ortopédica Mexicana. México.
}

Dirección para correspondencia:

M. Iván Encalada-Díaz

E-mail: encaladaiv@yahoo.com 